\title{
Efektivitas Limbah Debu Tembakau sebagai Insektisida Nabati terhadap Ulat Grayak
}

\author{
Yumna Aqilah Khairunnisa ${ }^{1 *}$, Sholahuddin ${ }^{1)}$, Ato Sulistyo ${ }^{1)}$
}

\begin{abstract}
Botanical pesticides produced from tobacco plants are reported to be the most toxic compared to other types of plants because it contain 2-8\% nicotine substances. The objective of this research was to examine the effect of tobacco dust waste extracts and determine the concentration of the most effective tobacco dust waste extract against armyworms. This research was conducted in Laboratory of Pest and Plant Disease and C Green House Faculty of Agriculture Universitas Sebelas Maret Surakarta from April-July 2018. The stages of this study include the multiplication of $S$. litura test larvae, preparation of botanical insecticides from tobacco dust waste, mortality test, antifeedant test and phytotoxicity test. This study used a completely randomized design with 6 treatments and 4 replications. The results showed that tobacco dust waste was able to increase the mortality of $S$. litura larvae, but with a slower effect compared to the treatment of profenofos. Feeding barriers are not seen in the test larvae. The phytotoxicity test shows that tobacco dust waste was not toxic to plants. Based on probit analysis, the concentration of tobacco dust waste which was capable of killing $50 \%$ of the population of $S$. litura was equal to $53.10 \mathrm{gL}^{-1}$.
\end{abstract}

Keywords: Biological control, Pest control, Vegetable pest

\section{PENDAHULUAN}

Hama merupakan salah satu faktor kendala dalam bidang pertanian. Salah satu hama daun penting yang mengakibatkan kehilangan hasil panen sebesar $20-40 \%$ adalah ulat grayak (BALITKABI 2008). Ulat grayak merupakan serangga hama polifag dari Ordo Lepidoptera, famili Noctuidae. Tanaman inang utamanya ialah kapas, padi, tomat, dan tembakau. Penelitian Cardona (2009), menjelaskan bahwa hama ulat grayak merupakan masalah utama dalam budidaya tanaman sayur-sayuran. Ulat grayak merupakan hama perusak daun yang bersifat polifag (mempunyai kisaran inang yang luas) (Pracaya 2011). Pengendalian ulat grayak perlu dilakukan untuk mengurangi kerugian hasil pada budidaya sayuran.

Pengendalian menggunakan pestisida sintetis yang tidak tepat mampu menyebabkan dampak negatif baik terhadap serangga, manusia dan juga lingkungan. Pengendalian ulat grayak dapat dilakukan salah satunya dengan pemanfaatan pestisida nabati. Pestisida nabati merupakan bahan aktif tunggal atau majemuk yang berasal dari tumbuhan yang bisa digunakan untuk mengendalikan organisme pengganggu tanaman. Pestisida nabati ini bisa berfungsi sebagai penolak, penarik, antifertilitas (pemandul), pembunuh, dan bentuk lainnya, karena terbuat dari bahan alami atau nabati, maka jenis pestisida ini bersifat mudah terurai (biodegradable) di alam, sehingga tak mencemari lingkungan dan relatif aman bagi manusia dan ternak peliharaan, karena residu (sisa-sisa zat) mudah hilang (Wiryadiputra 2003).

Pestisida nabati yang mampu dihasilkan dari tanaman tembakau dilaporkan yang paling toksik dibanding dari jenis tanaman lainnya dan memiliki nilai

1) Program Studi Agroteknologi, Fakultas Pertanian, Universitas Sebelas Maret

Author Contact: yumnaaqilah111@gmail.com
LD-50 (lethal dose 50\%) antara 50 dan 60 ppm. Daun tembakau kering mengandung $2-8 \%$ zat nikotin. Nikotin merupakan racun syaraf yang bereaksi cepat dan dapat berperan sebagai racun kontak bagi hama (Cloyd 2010). Batang dan daun tembakau yang telah dihaluskan mengandung 1.12 dan $1.10 \% \mathrm{~N} ; 0.84$ dan $0.31 \% \mathrm{P} 2 \mathrm{O} 5 ; 0.80$ dan $0.93 \% \mathrm{~K} 2 \mathrm{O}$ sehingga dapat mengurangi hama serangga (Pillai dan Muralidharan 2012). Penelitian ini bertujuan untuk mengkaji pengaruh ekstrak limbah debu tembakau dan mengetahui konsentrasi ekstrak limbah debu tembakau yang paling efektif terhadap ulat grayak.

\section{BAHAN DAN METODE}

Penelitian dilaksanakan di Laboratorium Hama dan Penyakit Tanaman dan Rumah Kaca C Fakultas Pertanian Universitas Sebelas Maret Surakarta pada April-Juli 2018. Bahan utama yang digunakan adalah limbah debu tembakau. Penelitian dilakukan dengan perbanyakan larva uji $S$. litura dengan mengambil telur ngengat $S$. litura yang ada di lahan. Persiapan insektisida nabati limbah debu tembakau perlu dilakukan sebelum melakukan pengujian, larutan insektisida nabati limbah debu tembakau diekstrak dengan cara merendam limbah debu tembakau sesuai konsentrasi dalam $1000 \mathrm{ml}$ aquades, kemudian disaring sebelum digunakan.

Setelah semua bahan tersedia kemudian dilakukan pengujian mortalitas dan antifeedant. Pengujian mortalitas dilakukan dengan menggunakan metode penyemprotan pada daun. Daun sawi uji disemprot dengan larutan uji sampai merata lalu dikeringanginkan. Sebanyak 15 ekor larva $S$. litura dimasukkan ke dalam wadah plastik yang diberi tutup kain kasa dan diberi daun perlakuan. Larva tersebut dibiarkan makan selama 24 jam. Setelah 24 jam (hari kedua) daun perlakuan diganti dengan daun tanpa perlakuan. Setiap perlakuan diulang 4 kali. Jumlah larva yang mati dicatat setiap hari sampai hari ke-4 (Abizar dan Prijono 2010). Pengujian antifeedant dilakukan dengan metode residu pada daun 
dengan metode tanpa pilihan (no choice test). Potongan daun perlakuan berukuran $15 \times 15 \mathrm{~cm}$ disemprot dengan bahan uji dan dikeringanginkan. Kemudian 1 ekor larva uji yang masih aktif makan diletakkan kedalam wadah plastik yang telah diberi daun perlakuan (Dadang dan Prijono 2008). Setelah 24 jam dihitung luas daun kontrol dan daun perlakuan yang dimakan setelah itu dihitung pengaruh hambatan makan larva (Lina et al. 2010). Uji selanjutnya yaitu pengujian fitotoksisitas. Tanaman sawi uji yang berusia 14 hari setelah tanam disiapkan. Larutan limbah tembakau serta kontrol disiapkan kemudian diaplikasikan pada tanaman uji dengan cara disemprotkan pada beberapa lembar daun pada tanaman tersebut. Pengamatan dilakukan dengan melihat perubahan fisiologis daun tanaman uji pada empat hari setelah perlakuan Pengujian dilakukan dengan 6 perlakuan dan 4 kali ulangan.

\section{HASIL DAN PEMBAHASAN}

\section{Mortalitas larva S. litura}

Hasil penelitian menunjukkan larutan limbah debu tembakau efektif menyebabkan mortalitas $S$. litura. Pemberian larutan tersebut pada larva uji menimbulkan gejala berupa; (1) perubahan warna, yaitu tubuh larva menjadi berwarna coklat kehitaman, selanjutnya larva menyusut dan berwarna hitam pekat (mati); (2) gagal molting, yaitu larva yang akan berganti kulit tubuhnya menjadi hijau pucat dan menjadi lembek; (3) larva yang masih hidup bergerak lambat dan mengalami penurunan aktivitas makan (Gambar 1). Herminanto et al. (2004) dalam penelitiannya menunjukkan bahwa larva yang terkena insektisida mematikan dapat mengalami perubahan fisiologis dan perilaku, sehingga dapat menghambat pertumbuhan termasuk gagalnya pembentukan pupa. Armaya (2005) menambahkan pengujian insektisida karbamat (Lannate $25 \mathrm{WP}$ ) pada hama ulat $S$. litura mengakibatkan kematian larva dengan kondisi kering menghitam.

Perlakuan limbah debu tembakau memberikan angka mortalitas yang lebih tinggi dibandingkan kontrol. Hal ini menunjukkan bahwa limbah debu tembakau mampu meningkatkan mortalitas $S$. litura, namun dengan efek yang lebih lambat dibandingkan dengan perlakuan Profenofos (Gambar 2). Perlakuan limbah debu tembakau untuk semua konsentrasi meningkatkan mortalitas S. litura pada 2 HSP, sedangkan Profenofos mampu meningkatkan mortalitas pada $1 \mathrm{HSP}$. Hal ini sesuai dengan yang diungkapkan oleh Sudarmo $S$ dan Mulyaningsih (2014) bahwa salah satu kelemahan pestisida nabati adalah daya racun yang rendah sehingga tidak langsung mematikan serangga.

Berdasarkan penelitian, mortalitas larva dengan perlakuan limbah tembakau berbeda nyata dengan kontrol. Hasil terbaik terdapat pada konsentrasi $60 \mathrm{gL}^{-1}$ yaitu sebesar $96.65 \%$ (Tabel 1). Larutan limbah debu tembakau cukup baik dalam mempengaruhi mortalitas larva $S$. litura karena banyaknya total larva yang mati. Perlakuan limbah debu tembakau untuk semua konsentrasi mampu menyebabkan mortalitas diatas $60 \%$. Oleh karena itu, limbah debu tembakau memiliki potensi untuk menggantikan insektisida kimia.
Satu larva $S$. litura perlakuan limbah debu tembakau $30 \mathrm{gL}^{-1}$ dan $45 \mathrm{gL}^{-1}$ menghilang pada ulangan 1 . Kanibalisme diduga menjadi penyebab hilangnya larvalarva tersebut, karena tidak ditemukan bangkai pada wadah perlakuan. Kalshoven (1981) menyatakan bahwa faktor penghambat laju populasi $S$. litura adalah sifatnya yang kanibal.

Mortalitas $S$. litura tidak hanya disebabkan oleh perlakuan-perlakuan yang diberikan. Kelembaban yang tinggi diduga menjadi salah satu penyebab mortalitas S. litura. Liu et al. (2012) dalam penelitiannya menunjukkan adanya pengaruh suhu dalam mempengaruhi perkembangan larva. Ngowi et al. (2017) menambahkan bahwa suhu yang baik dalam keberhasilan hidup ordo lepidoptera pada fase larva dan pupa sekitar $20^{\circ} \mathrm{C}$.

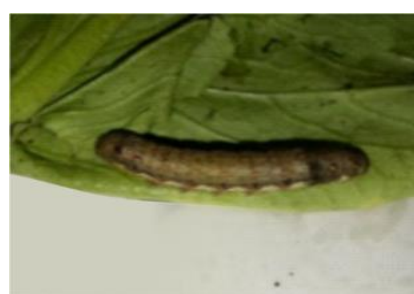

(a)

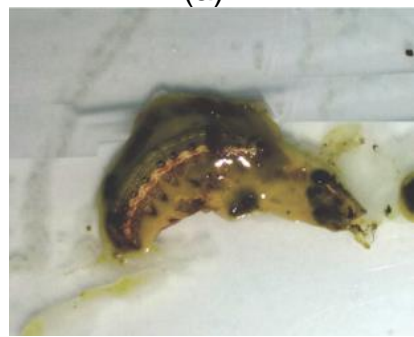

(c)

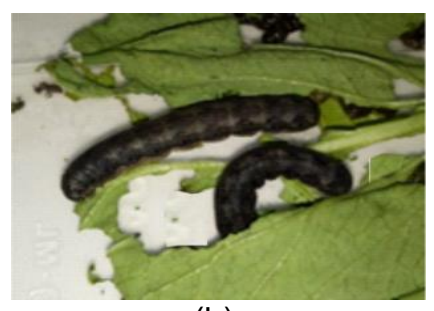

(b)

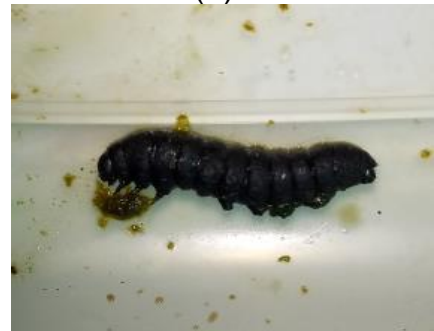

(d)
Keterangan: (a) Larva sehat, (b) Larva sakit, (c) Larva gagal molting, (d) Larva mati

Gambar 1. Mortalitas larva S. litura akibat perlakuan dengan limbah debu tembakau.

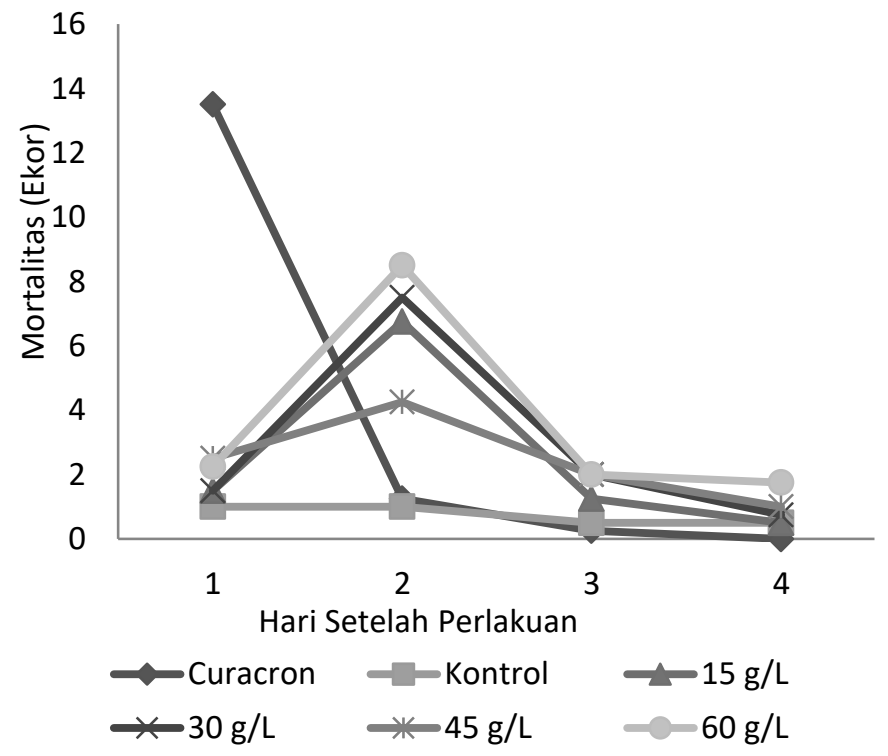

Gambar 2. Limbah debu tembakau terhadap mortalitas larva S. litura 
Tabel 1. Pengaruh aplikasi limbah debu tembakau terhadap mortalitas larva S. litura

\begin{tabular}{|c|c|c|c|c|c|}
\hline \multirow{2}{*}{ Perlakuan( $\mathrm{gL}^{-1)}$} & \multicolumn{4}{|c|}{ Ulangan } & \multirow{2}{*}{ Rata-rata Mortalitas $(\%) \pm \mathrm{SB}^{1)}$} \\
\hline & 1 & 2 & 3 & 4 & \\
\hline Profenofos & 100,00 & 100,00 & 100,00 & 100,00 & $\pm 0,00 \quad c^{(2)}$ \\
\hline Tanpa perlakuan & 20,00 & 20,00 & 26,60 & 13,30 & $\pm 5,43$ a \\
\hline 15 & 80,00 & 66,60 & 80,00 & 40,00 & $66,60 \pm 18,85 b$ \\
\hline 30 & 86,60 & 73,30 & 73,30 & 80,00 & $78,30 \quad \pm 6,37 \quad b$ \\
\hline 45 & 80,00 & 66,60 & 66,60 & 46,60 & $64,95 \pm 13,76 b$ \\
\hline 60 & 100,00 & 93,30 & 100,00 & 93,30 & $96,65 \quad \pm 3,86 \quad c$ \\
\hline
\end{tabular}

1) $\mathrm{SB}=$ Simpangan Baku (standar deviasi)

2) Angka yang diikuti oleh huruf yang sama menunjukkan tidak berbeda nyata pada uji DMRT taraf $5 \%$

\section{Fitotoksisitas limbah debu tembakau}

Hasil pengujian menunjukkan bahwa tidak adanya gejala fitotoksisitas terhadap tanaman uji pada 4 HSP dengan 5 perlakuan konsentrasi. Hal ini dibuktikan dengan tidak ditemukannya gejala fitotoksik yang menurut Ibrahim et al. (2009) antara lain: permukaan, tepi, atau seluruh daun dapat terbakar; nekrosis atau menguningnya daun (titik atau tepi) atau nekrosis diseluruh daun; dan daun menjadi keriting, berkerut, melengkung kedalam (Gambar 3). Hasil penelitian menunjukkan penggunaan limbah debu tembakau tidak meracuni tanaman.

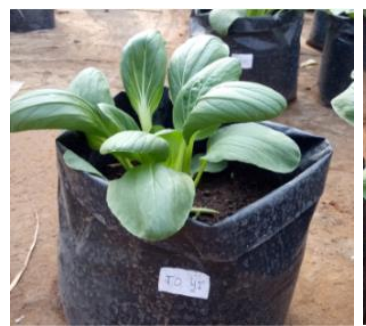

(a)

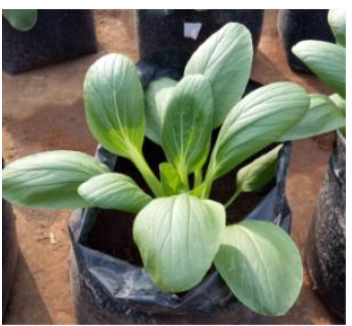

(b)

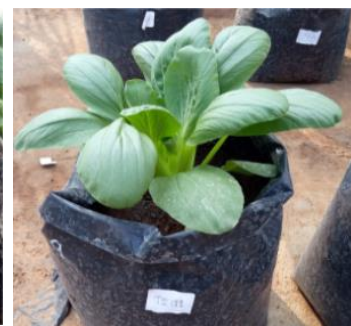

(c)
Kandungan limbah debu tembakau dengan konsentrasi $15 \mathrm{gL}^{-1}, 30 \mathrm{gL}^{-1}, 45 \mathrm{gL}^{-1}$ dan $60 \mathrm{gL}^{-1}$ tidak bersifat racun terhadap tanaman. Pemberian limbah debu tembakau dengan konsentrasi tersebut diduga sudah sesuai, karena tidak adanya gejala kerusakan yang timbul. Jimenez et al. (2012) dalam penelitiannya menunjukkan debu tembakau yang mengandung arsen bila diaplikasikan ke tanaman terlalu banyak akan menyebabkan terjadinya keracunan pada tanaman yang ditandai dengan hambatan pertumbuhan, degradasi klorofil, deplesi hara dan cekaman oksidatif.

Gambar 3. Tanaman sawi uji dengan perlakuan limbah debu tembakau (a) Kontrol, (b) $15 \mathrm{gL}^{-1}$, (c) $30 \mathrm{gL}^{-1}$, (d) $45 \mathrm{gL}^{-1}$, (e) $60 \mathrm{gL}^{-1}$

\section{Daya racun limbah debu tembakau}

Limbah debu tembakau memiliki aktivitas insektisida yang cukup kuat terhadap larva $S$. litura instar III. Berdasar hasil penelitian, konsentrasi $60 \mathrm{gL}^{-1}$ larutan uji mampu mengakibatkan mortalitas larva sebesar $96 \%$. Menurut Laba dan Soekarna (1986) suatu insektisida dikatakan efektif apabila mampu mematikan minimal $80 \%$ serangga uji. Berdasarkan analisis probit limbah debu tembakau memiliki efek toksik yang kuat terhadap $S$. litura instar III. Limbah debu tembakau yang diberikan pada $S$. litura instar III didapat $\mathrm{LC}_{50}$ sebesar $53.10 \mathrm{gL}^{-1}$ sedangkan $\mathrm{LC}_{90}$ sebesar $59.77 \mathrm{gL}^{-1}$. Artinya bahwa pada konsentrasi $53.10 \mathrm{gL}^{-1}$ limbah debu tembakau mampu membunuh $50 \%$ larva $S$. litura dengan batas bawah $27.95 \mathrm{gL}^{-1}$ dan batas atas $58.32 \mathrm{gL}^{-1}$. Sedangkan pada konsentrasi $59.77 \mathrm{gL}^{-1}$ limbah debu tembakau mampu membunuh $90 \% \mathrm{~S}$. litura dengan batas bawah $53.93 \mathrm{gL}$ ${ }^{1}$ dan batas atas $77.83 \mathrm{gL}^{-1}$. Argo (2001) menyatakan bahwa semakin kecil nilai $\mathrm{LC}_{50}$ suatu bahan kimia maka akan semakin toksik senyawa tersebut dan apabila semakin besar nilai $\mathrm{LC}_{50}$ maka semakin rendah toksisitasnya.
Tabel 2. Daya racun limbah debu tembakau terhadap $S$. litura

\begin{tabular}{cccc}
\hline \multirow{2}{*}{$\mathrm{LC}$} & \multirow{2}{*}{ Konsentrasi } & \multicolumn{2}{c}{ Interval } \\
\cline { 3 - 4 } & & Batas Bawah & Batas Atas \\
\hline $\mathrm{LC}_{50}$ & $53,10 \mathrm{gL}^{-1}$ & $27,95 \mathrm{gL}^{-1}$ & $58,32 \mathrm{gL}^{-1}$ \\
$\mathrm{LC}_{90}$ & $59,77 \mathrm{gL}^{-1}$ & $53,93 \mathrm{gL}^{-1}$ & $77,83 \mathrm{gL}^{-1}$ \\
\hline
\end{tabular}

\section{Hambatan aktivitas makan S. litura}

Pengaruh hambatan makan terhadap limbah debu tembakau tidak tampak pada larva uji. Hal ini diduga karena kandungan fenol dari limbah debu tembakau tergolong rendah. Bernays dan Chapman (1994) menyatakan kandungan lignin (sumber senyawa fenol) dari asap cair tempurung kelapa menunjukkan pengaruh antifeedant yang tinggi terhadap larva $S$. litura. Luas daun yang dimakan oleh larva pada perlakuan limbah debu tembakau tidak berbeda nyata dengan kontrol. Perbedaan luas daun yang di makan larva S. litura pada setiap perlakuan limbah debu tembakau bervariasi. Luas daun tertinggi yang dimakan $S$. litura terdapat pada perlakuan limbah debu tembakau $45 \mathrm{gL}^{-1}$ yaitu 
$176.99 \mathrm{~cm}^{2}$. Sedangkan luas daun terkecil yang dimakan S. litura terdapat pada perlakuan Profenofos yaitu 56.25 $\mathrm{cm}^{2}$ (Gambar 4). Larutan limbah debu tembakau diduga membutuhkan waktu yang lama untuk dapat menghambat aktivitas makan larva $S$. litura.

Kemampuan makan yang tinggi pada fase larva di setiap perlakuan menunjukkan rendahnya hambatan makan larva. Beberapa penelitian menunjukkan adanya resistensi pada Lepidoptera terhadap pestisida kimia seperti profenofos, fipronil (Moekasan et al. 2004),

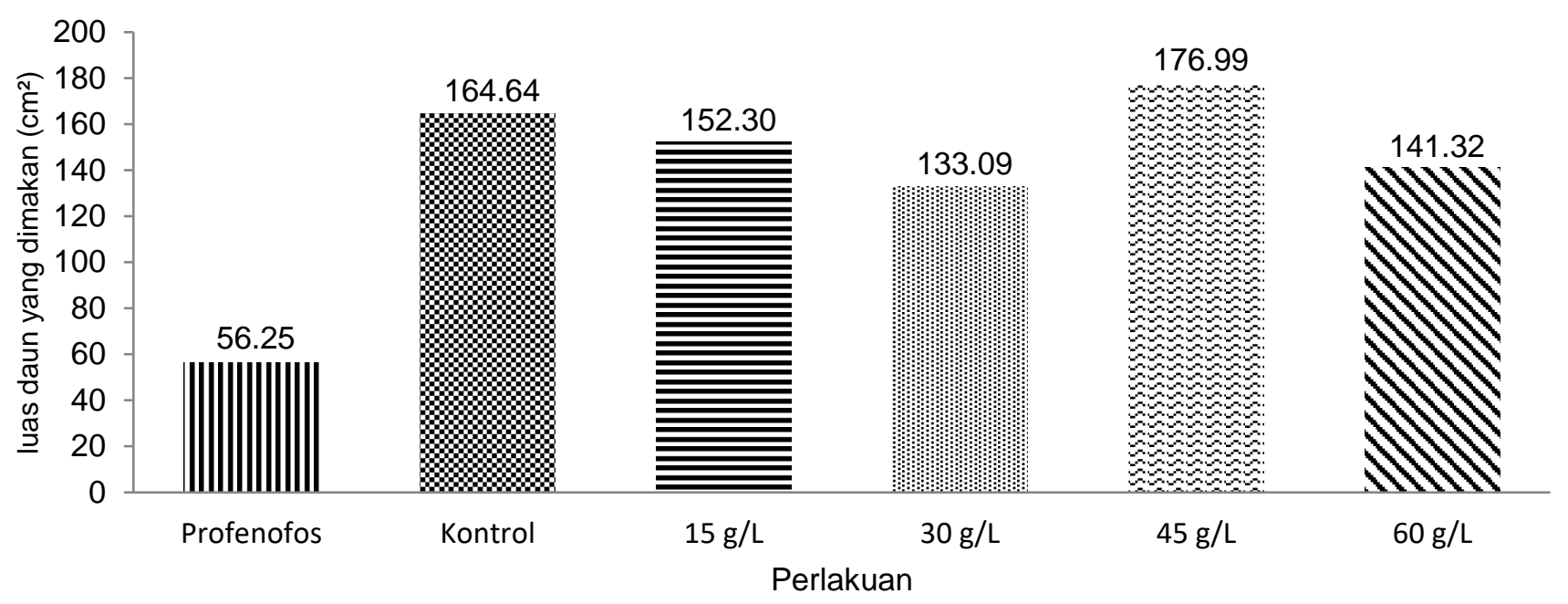

Gambar 3. Luas daun yang di makan larva S.litura setelah perlakuan limbah debu tembakau

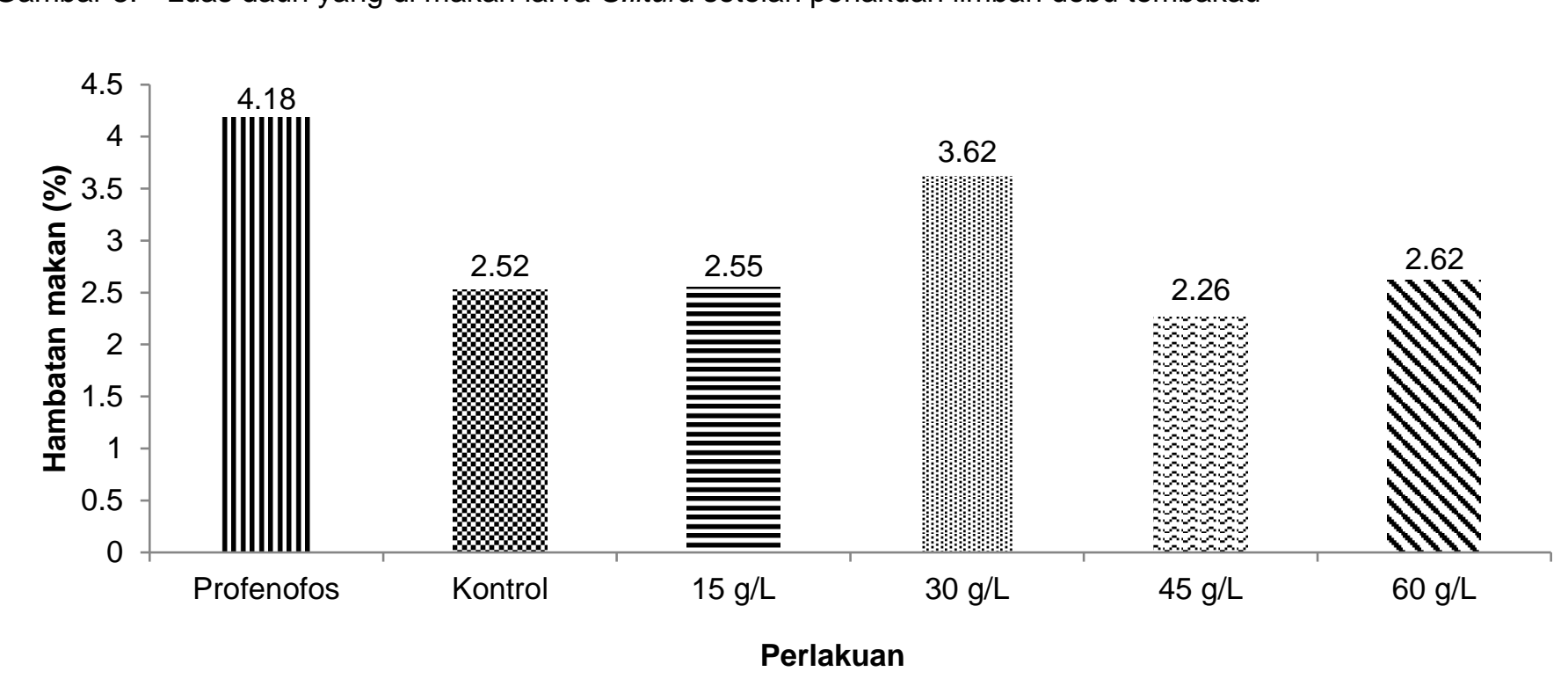

abamectin, cypermethrin, monosulap (Zhou et al. 2011), dan cholantraniliprole (Wang dan Wu 2012). Persentase hambatan makan menunjukkan hasil tidak berbeda nyata. Rata-rata hambatan makan tertinggi terdapat pada perlakuan Profenofos sebesar $4.17 \%$. Konsentrasi $45 \mathrm{gL}^{-1}$ menunjukkan hambatan makan terkecil yaitu sebesar $2.26 \%$. Kontrol sebesar $2.52 \%$ menunjukkan hasil hambatan makan yang tidak berbeda jauh dari perlakuan limbah debu tembakau. (Gambar 5).

Gambar 4. Rata-rata hambatan aktivitas makan larva S.litura karena perlakuan limbah debu tembakau.

\section{KESIMPULAN}

Limbah debu tembakau memiliki pengaruh terhadap larva $S$. litura instar III yaitu, perlakuan limbah debu tembakau paling efektif menyebabkan mortalitas tertinggi S. litura pada konsentrasi $60 \mathrm{gL}^{-1}$. Aplikasi limbah debu tembakau pada sawi dengan konsentrasi hingga $60 \mathrm{gL}^{-1}$ tidak mempengaruhi hambatan makan S. litura dan tidak menimbulkan efek fitotoksik pada tanaman sawi uji. LC Lo $_{50}$ dari limbah debu tembakau terhadap larva $S$. litura instar III adalah $53.10 \mathrm{gL}^{-1}$.

\section{DAFTAR PUSTAKA}

Abizar M, Prijono D. 2010. Kesesuaian ekstrak Piper spp. (Piperaceae) untuk meningkatkan toksisitas ekstrak Tephorosia vogelii terhadap ulat krop kubis Crocidolomia pavonana. J. Hama Penyakit dan Tumbuhan Tropika. 10:1-12.

Argo D, Imono. 2001. Toksikologi dasar. Laboratorium Farmakologi dan Toksikologi. Universitas Gadjah Mada, Yogyakarta.

Armaya D. 2005. Uji efektivitas beberapa jenis insektisida untuk mengendalikan hama ulat Spodoptera litura F. pada tanaman tembakau Deli (Nicotiana tobacco L.). Universitas Sumatera Utara, Medan. 
[BALITKABI] Balai Penelitian Tanaman Kacangkacangan dan Umbi-umbian. 2008. Pengendalian dan Komponen Teknologi Pengendalian Ulat Grayak (Spodoptera litura Fabricus) Pada Tanaman Kedelai, Malang.

Bernays EA, Chapman RF. 1994. Plant Selection by Phytophagus-insect. Chapman \& Hall One Penn Plaza. New York. 312 pp.

Cardona EV, Ligat CS, Subang MP. 2009. Life History of Common Cutworm, Spodoptera Litura Fabricius (Noctuidae; Lepidoptera) In Benguet. Progress Report. BSU Research In- House Review

Cloyd RA. 2010. Natural Indeed: Are natural insecticides safer and better than conventional insecticides. Illinois Pesticides Review, 17, 3-6.

Dadang dan Prijono. 2008. Insektisida nabati: Prinsip, pemanfaatan dan pengembangan. Departemen Proteksi Tanaman. Institut Pertanian Bogor, Bogor.

Herminanto, Wirashi, Sumarsono T. 2004. Potensi ekstrak biji srikaya (Annona squamosa L.) untuk mengendalikan ulat krop kubis Crocidolomia pavonana F. J. Agrosains. 6(1): 31-35.

Ibrahim M, Franco M, Pezo DA, Camero A, Araya JL. 2009. Promoting intake of Cratylia argentea as a dry season supplement for cattle grazing Hyparrhenia rufa in the subhumid tropics. Agroforestry Systems. 51 (2): 167-175

Jimenez EM, Esteban E, dan Penalosa JM. 2012. The fate in soil-plant systems. Reviews of environmental contamination and toxicology. 215: 1-27. DOI: 10.1007/978-1-4614-1463-6_1

Kalshoven LGE. 1981. The Pest of Crops in Indonesia. Jakarta: PT-Ictiar baru.

Laba IW dan Soekarna D. 1986. Mortalitas ulat grayak (Spodoptera litura F.) pada berbagai instar dan perlakuan insektisida pada kedelai. Makalah Seminar Hasil Penelitian Tanaman Pangan. Bogor: Balai Penelitian dan Pengembangan Tanaman Pangan.

Lina SR, Fei R, Xudong Z, Yangong D, Fa H. 2010. Supercritical carbon dioxide extraction of seed oil. J. Am. Oil Chem. Soc. 87: 1221-1226.
Liu SS, Chen FZ, Zalucki MP. 2012. Development and survival of the diamondback moth (lepidoptera: plutellidae) at constant and alternating temperatures. Environ. Entomol. 31(2): 221-231. DOI: 10.1603/0046-225X-31.2.221.

Makal HVG dan Turang DAS. 2011. Pemanfaatan ekstrak kasar batang serai untuk pengendalian larva Crosidolomia binotalis Zell. Pada tanaman kubis. Eugenia 17(1): 16-20.

Ngowi BV, Henri E. Z. T., Evans M. M., Tino J., Janet A., Paul N. N., and Sevgan S. 2017. Temperature-dependent phenology of Plutella xylostella (Lepidoptera: Plutellidae): Simulation and visualization of current and future distributions along the Eastern Afromontane. Plos One. 1-24.

Pillai S, Muralidharan. 2012. Effect of tobacco waste on the enhanced productivity of tomato plants. Proceeding of International Conference on Agriculture, Science and Engineering (ICASE 2012). Port Harcourt-Nigeria, 3-7 September 2012. African Society for the Scientific Research (assr). P97-109.

Pracaya 2011. Hama dan Penyakit Tanaman. Penebar Swadaya, Jakarta.

Sudarmo S, Mulyaningsih S. 2014. Mudah Membuat Pestisida Nabati Ampuh. AgroMedia Pustaka, Jakarta.

Wang $X$ and Wu Y. 2012. High levels of resistance to chlorantraniliprole evolved in field populations of Plutella xylostella. J. Of Econo. Entomo. 105(3): 1019-1023.

Wiryadiputra S. 2003. Kefektifan limbah tembakau sebagai insektisida nabati hayati untuk mengendalikan hama Helopeltis sp. pada kakao. J. Perlindungan Tanaman Indonesia (9)35-45.

Zhou L, Huang J, Xu H. 2011. Monitoring resistance of field populations of diamondback moth (Lepidoptera: Yponomeutidae) to five insecticides in South China: A ten-year case study. Crop Protection 30: 272-278. 